\title{
Primary cutaneous B-cell lymphoma: Role of surgery
}

\author{
Sam Parbhakar MD FRCSC ${ }^{1}$, Arianna Dal Cin MD FRCSC ${ }^{1,2}$
}

S Parbhakar, A Dal Cin. Primary cutaneous B-cell lymphoma: Role of surgery. Can J Plast Surg 2011;19(2):e12-e14.

PURPOSE: To evaluate the role of surgery in patients diagnosed with primary cutaneous B-cell lymphoma (PCBCL) - a rare disease entity. The authors offer a rationale for the use of primary surgical excision in the treatment of isolated cutaneous lymphomas.

METHODS: A literature review examining the use of primary surgical excision in the treatment of PCBCL was conducted. The lymphoma database at the Juravinski Cancer Centre (Hamilton, Ontario) was searched from January 1995 to July 2008, generating a list of 4924 patients. A simulated computer program was subsequently designed to search for all possible PCBCLs. A retrospective chart review was then conducted on the new list of 1325 patients, identifying 25 patients diagnosed with PCBCL.

RESULTS: The mean age of the 25 patients with PCBCL was 59.9 years; nine $(36 \%)$ were treated with surgery, and sixteen $(64 \%)$ with radiation. The average follow-up period for patients was 3.6 years. Twenty-four of the 25 patients were completely cured, with only one patient recurring in the radiation subgroup. There were no complications in the surgery subgroup. There were two local complications in the radiation subgroup consisting of chronic ulcerations.

CONCLUSIONS: Primary surgical excision is an effective management option in the treatment of PCBCL, particularly the marginal zone and follicle centre subtypes.

Key Words: B-cell lymphoma; Cutaneous lymphoma; Surgery

\section{Le lymphome à lymphocytes $\mathrm{B}$ cutané primaire : le rôle de la chirurgie}

OBJECTIF : Évaluer le rôle de la chirurgie chez les patients ayant un diagnostic de lymphome à lymphocytes B cutané primaire (LLBCP), une entité pathologique rare. Les auteurs justifient le recours à l'excision chirurgicale primaire pour traiter les lymphomes cutanés isolés.

MÉTHODOLOGIE : Les chercheurs ont procédé à une analyse bibliographique sur l'utilisation de l'excision chirurgicale primaire pour traiter le LLBCP. Ils ont effectué une recherche dans la base de données des lymphomes du Juravinski Cancer Centre de Hamilton, en Ontario, entre janvier 1995 et juillet 2008, et ont obtenu une liste de 4924 patients. Ils ont ensuite conçu un programme informatique simulé pour chercher toutes les possibilités de LLBCP. Ils ont ainsi effectué un examen rétrospectif des dossiers des 1325 nouveaux patients et repéré 25 patients ayant un diagnostic de LLBCP.

RÉSULTATS : Les 25 patients ayant un LLBCP avaient un âge moyen de 59,9 ans. Neuf (36\%) ont été traités par chirurgie et 16 (64\%) par radiation. Les patients ont vécu une période de suivi moyenne de 3,6 ans. Vingt-quatre des 25 patients ont complètement guéri, et un seul patient a fait une rechute, dans le sous-groupe ayant subi la radiation. Aucune complication n'a été observée dans le sous-groupe ayant subi une chirurgie, mais on a constaté deux complications locales d'ulcères chroniques dans le sous-groupe ayant subi la radiation.

CONCLUSION : L'excision chirurgicale primaire constitue une possibilité de prise en charge efficace pour traiter le LLBCP, notamment dans les soustypes de la zone marginale et du centre folliculaire.
$\mathrm{T}$ here has been a significant amount of confusion regarding the definition, terminology and optimal treatment of primary cutaneous B-cell lymphoma (PCBCL). Primary cutaneous lymphomas represent $7.5 \%$ of all lymphomas (1-4). PCBCLs are much less common than primary cutaneous T-cell lymphomas, and constitute approximately $20 \%$ to $25 \%$ of all primary cutaneous lymphomas $(3,4)$.

PCBCL is defined as a non-Hodgkin B-cell lymphoma originating in the skin, with no evidence of extracutaneous manifestations over a period of six months when complete staging has been performed (5). The WHO and the European Organization for the Research and Treatment of Cancer recognize four main types of PCBCL: primary cutaneous marginal zone B-cell lymphoma, primary cutaneous follicle centre lymphoma, large PCBCLs (leg type) and diffuse large PCBCLs (other) $(1,4,6,7)$.

It is important to differentiate these PCBCLs from systemic nodal B-cell lymphomas with skin involvement because the latter disease entity exhibits a completely different clinical behaviour, has a poor prognosis and requires aggressive therapeutic regimens. Conversely, PCBCLs respond favourably to local treatment and have an excellent prognosis. Staging evaluation is necessary to confirm a diagnosis of PCBCL, and to exclude systemic nodal B-cell lymphoma. This evaluation includes biopsies for histopathology, immunophenotyping, bone marrow biopsy, and a computed tomography scan of the chest, abdomen and pelvis (8). Diagnosis of PCBCL is reached when clinical and histological assessment is combined with the identification of prognostic factors in the absence of dissemination (5). The recognized standard treatment of PCBCL marginal zone and follicle centre subtypes is radiation, with much of the evidence derived from the oncology literature $(1,2,4,5,9)$. The standard treatment of radiation consists of a median dose of 3000 centigray (cGy) to $4000 \mathrm{cGy}$ over a period of six weeks. There is literature that supports the use of surgical excision as an option for PCBCL; however, it is minimal $(1,10,11)$.

The overall purpose of the present retrospective study was to first identify any patients with PCBCL in the cancer database at the Juravinski Cancer Centre (Hamilton, Ontario) and to re-examine their classification and coding using The International Classification of Diseases. The next important goal was to show that primary surgical excision is an effective management option, and to subsequently prevent patients with marginal zone and follicle centre PCBCLs from being treated with overly aggressive radiation and chemotherapy.

\section{PATIENTS AND METHODS}

Before study initiation, a literature review was conducted using the OVID Medline, PubMed and Embase databases to search for PCBCL and the use of primary surgical excision as a treatment option. Following this, the entire lymphoma database at the Juravinski Cancer Centre was searched between January 1995 and July 2008, which generated a total of 4924 patients with B-cell lymphoma diagnosis. The next challenge was to identify patients with PCBCL, and to exclude patients with systemic nodal B-cell lymphoma. The difficulty was that all of the patients with PCBCL were broadly classified. To isolate patients with PCBCL, a simulated computer program was designed with the help of the information technology team at the Juravinski Cancer Centre.

\footnotetext{
${ }^{1}$ Division of Plastic Surgery, ${ }^{2}$ Department of Surgery and Oncology, McMaster University, Hamilton, Ontario

Correspondence: Dr Arianna Dal Cin, Division of Plastic Surgery, Department of Surgery, McMaster University, 504-304 Victoria Avenue North,

Hamilton, Ontario L8L 5G4. Telephone 905-526-0811, fax 905-526-0890, e-mail dalcin@hhsc.ca
} 
TABLE 1

Patient characteristics of the radiation subgroup $(n=16)$

\begin{tabular}{lc}
\hline & Results \\
\hline Sex, $\mathrm{n}(\%)$ & $8(50)$ \\
Male & $8(50)$ \\
Female & \\
Age, years & $62.1(36-84)$ \\
$\quad$ Mean (range) & \\
Medical comorbidities, $\mathrm{n}$ & 2 \\
Diabetes & 2 \\
Cardiovascular disease & 1 \\
Cerebrovascular disease & 1 \\
Peripheral vascular disease & \\
Histological subtypes (WHO), $\mathrm{n}(\%)$ & $7(43.8)$ \\
Marginal zone & $7(43.8)$ \\
Follicle centre & $2(12.5)$ \\
Large B-cell & \\
Tumour location, $\mathrm{n}(\%)$ & $8(50)$ \\
Head/scalp & $4(25)$ \\
Trunk & $4(25)$ \\
Extremity & 3.75 \\
Follow-up, years & $1(6.3)$ \\
Recurrence, $\mathrm{n}(\%)$ & \\
Complications, $\mathrm{n}(\%)$ & $2(12.5)$ \\
Local & $0(0)$ \\
Systemic &
\end{tabular}

This reduced the total number to 1325 patients with a possible diagnosis of PCBCL.

A retrospective chart review of these 1325 patients was conducted. The essential criteria for a diagnosis of PCBCL was non-Hodgkin's B-cell lymphoma with the absence of any extracutaneous lesions over a period of six months. PCBCL diagnosis was confirmed with immunophenotyping and the expression of B-cell-restricted antigens CD20, CD79a, bcl2+ and bcl6+. All cases were classified according to the WHO criteria.

After conducting the present, extensive, retrospective chart review, a total of 25 patients with PCBCL diagnosis were identified. All 25 patients were treated with either radiation or surgery. The outcome measured among these 25 patients was the cure rate (five-year disease-free survival) and the recurrence of PCBCL. In addition, the local and systemic complications associated with radiation or surgical treatment were analyzed.

\section{RESULTS}

The 25 patients identified with PCBCL represented $1.8 \%$ of the 1325 cases of non-Hodgkin's lymphoma in the Juravinski Cancer Centre database that were retrospectively reviewed. Sixteen of 25 patients were treated with radiation, with a median dose of 3000 cGy to 4000 cGy, 10 fractions and a treatment length of approximately six weeks. Nine of 25 patients were treated with surgical excision with $5 \mathrm{~mm}$ margins, and the fresh lymphoma specimen was sent for histology and immunophenotyping. The characteristics and results of the patient populations treated with radiation and surgery are outlined in Tables 1 and 2, respectively.

The mean age of the combined patient population $(n=25 ; 12$ men and 13 women) was 59.9 years. For patients treated with radiation $(n=16)$, the mean age was 62.1 years (range 36 to 84 years), with eight men and eight women. For patients treated with surgical excision $(n=9)$, the mean age was 56 years (range 33 to 91 years), with four men and five women.

Among all patients $(n=25)$, the histological subtypes of the PCBCL were as follows: 13 (52\%) marginal zone, 10 (40\%) follicle centre and two
TABLE 2

Patient characteristics of the surgery subgroup $(n=9)$

\begin{tabular}{lc}
\hline & Results \\
\hline Sex, $\mathrm{n}(\%)$ & $4(44.4)$ \\
Male & $5(55.6)$ \\
Female & \\
Age, years & $56(33-91)$ \\
$\quad$ Mean (range) & \\
Medical comorbidities, $\mathrm{n}$ & 1 \\
Diabetes & 1 \\
Cardiovascular disease & 1 \\
Panic disorder & \\
Histological subtypes (WHO), $\mathrm{n}(\%)$ & $6(66.7)$ \\
Marginal zone & $3(33.3)$ \\
Follicle centre & \\
Tumour location, $\mathrm{n}(\%)$ & $4(44.4)$ \\
Head/scalp & $3(33.3)$ \\
Trunk & $2(22.2)$ \\
Extremity & 4.2 \\
Follow-up, years & $0(0)$ \\
Recurrence, $\mathrm{n}(\%)$ & \\
Complications, $\mathrm{n}(\%)$ & $0(0)$ \\
Local & $0(0)$ \\
Systemic &
\end{tabular}

(8\%) large B-cell. The histological subtypes of the PCBCL in the radiation subgroup $(n=16)$ were as follows: seven $(43.8 \%)$ marginal zone, seven $(43.8 \%)$ follicle centre and two (12.5\%) large B-cell. By comparison, in the surgical subgroup $(n=9)$, the histological subtypes were as follows: six $(66.7 \%)$ marginal zone and three $(33.3 \%)$ follicle centre.

The location of the PCBCL was divided into three regions: the head/scalp region, the trunk region and the extremities. Overall, the location of the PCBCL in the different regions was as follows: $12(48 \%)$ in the head/scalp region, seven $(28 \%)$ in the trunk region and six $(24 \%)$ in the extremities. In the radiation subgroup, the distribution of the PCBCL location in the patients was as follows: eight $(50 \%)$ in the head/scalp region, four $(25 \%)$ in the trunk region and four $(25 \%)$ in the extremities. In the surgery subgroup, the distribution of the PCBCL was as follows: four $(44.4 \%)$ in head/scalp region, three $(33.3 \%)$ in the trunk region and two $(22.2 \%)$ in the extremities.

The cure rate (five-year disease-free survival) was $96 \%-24$ of 25 patients treated with either radiation or surgery were disease free. Only one of 25 patients (4\%) experienced PCBCL recurrence. In the radiation subgroup, one of 16 patients $(6.3 \%)$ experienced recurrence. This recurrence occurred at two years, and the lymphoma was treated with surgical excision with $5 \mathrm{~mm}$ margins. This patient did not experience any additional recurrences five years following surgery. In the surgery subgroup, none of the nine patients $(0 \%)$ experienced recurrence. Both treatment groups had adequate follow-up periods. The overall median follow-up period $(n=25)$ was 3.6 years. The radiation subgroup follow-up period was 3.75 years. By comparison, the surgical subgroup follow-up period was 4.2 years (Tables 1 and 2).

Local and systemic complications from radiation and surgery were analyzed in the 25 patients with PCBCL. There were no systemic complications associated with the radiation subgroup (zero of 16) or the surgical subgroup (zero of 9). With regard to local complications associated with radiation, two of 16 patients experienced chronic nonhealing ulcerations in the PCBCL area, and 14 of 16 patients experienced skin changes (including erythema, itching and swelling) often seen after treatment. These changes lasted an average of 1.6 years after the final treatment. In the surgical subgroup, none of the nine patients experienced local complications. 


\section{DISCUSSION}

The first important issue recognized in the present retrospective study was the systemic coding of all the PCBCL patients in our institution's cancer database. The lymphoma database at the Juravinski Cancer Centre initially identified 4924 patients; this number was reduced, with the help of a simulated computer program, to 1325 patients, who were retrospectively reviewed. The most striking finding was that all 25 patients were broadly coded as having systemic B-cell lymphoma or a pseudolymphoma. Clearly, one of the goals of the present study is to recognize all physicians that PCBCL is a separate disease entity that differs from systemic nodal B-cell lymphoma. It has a favourable prognosis and requires less aggressive therapeutic regimens.

The age, sex and incidence of PCBCL patients in the present retrospective review correspond to results reported in previous published series (1-3). For the majority of patients, the distribution of lesions was in the head and neck region; 12 of 25 patients (25\%) presented with PCBCL in this region. Overall, in the present retrospective study of 25 patients with PCBCL, the radiation treatment subgroup and the surgical treatment subgroup were similar with regard to most patient characteristics and treatment outcomes. Only one of 16 patients $(16.3 \%)$ in the radiation treatment subgroup experienced recurrence. By comparison, none of the nine patients in the surgery treatment group experienced recurrence. With regard to local complications in the radiation treatment subgroup, two of 16 patients experienced chronic ulcerations in the PCBCL area, and 14 of 16 patients experienced erythema and swelling of the skin for an average of 1.6 years. By comparison, there were no local or systemic complications in the surgery treatment subgroup. These results suggest that surgery is an equally effective treatment option for PCBCL, with the added advantage of preventing unwanted local complications that may be associated with radiation. In the literature on PCBCL, the first-line treatment for PCBCL, and marginal zone and follicle centre PCBCL subtypes, is radiation, with surgical excision being listed as a second-line treatment (4). The first-line treatment in the literature is radiation, and the second-line treatment includes chemotherapy and monoclonal antibodies (4). With the results obtained from the present study, serious consideration should be given to adding surgical excision to the first-line treatment options that are offered to patients with PCBCL with the marginal zone and follicle centre subtypes. In the large B-cell subtype of PCBCL, the prognosis is poorer than for the marginal zone and follicle centre subtypes. The five-year diseasefree survival rate of the large B-cell subtype is 50\% compared with $95 \%$ for the marginal zone and follicle centre subtypes.
The obvious disadvantage of the present study was the small sample size obtained for PCBCL from the lymphoma database. The next step would be to conduct a multicentre study with other lymphoma databases across North America to increase the sample size to allow for more rigorous statistical analysis.

\section{CONCLUSION}

On the basis of the results obtained, primary surgical excision is an effective management option in the treatment of PCBCL, particularly for the marginal zone and follicle centre histological subtypes.

NOTE: No benefits were received or will be received from a commercial party related directly or indirectly to the subject of the present article.

\section{REFERENCES}

1. El-Helw L, Goodwin S, Slater D, Hancock BW. Primary B-cell lymphoma of the skin: The Sheffield Lymphoma Group Experience (1984-2003). Int J Oncol 2004;25:1453-8.

2. Dreno B. Standard and new treatments in cutaneous B-cell lymphomas. J Cutan Pathol 2006;(33 Suppl 1):47-51.

3. Kerl H, Cerroni L. Primary cutaneous B-cell lymphomas: Then and now. J Cutan Pathol 2006;(33 Suppl 1):1-5.

4. Willemze R. Primary cutaneous B-cell lymphoma: Classification and treatment. Curr Opin Oncol 2006;18:425-31.

5. Querfeld C, Guitart J, Kuzel TM, Rosen ST. Primary cutaneous lymphomas: A review with current treatment options Blood Rev 2003;17:131-42.

6. Assaf C, Steinhoff M, Gellrich S, Sterry W. Classification of primary cutaneous lymphomas. Front Radiat Ther Oncol 2006;39:25-37.

7. Dummer R, Cozzio A, Urosevic M. Pathogenesis and therapy of cutaneous lymphomas - progress or impasse? Exp Dermatol 2006;15:392-400.

8. Demierre MF, Kerl H, Willemze R. Primary cutaneous B-cell lymphomas: A practical approach. Hematol Oncol Clin North Am 2003;17:1333-50.

9. Yasukawa K, Kato N, Kodama K, Hamasaka A, Hata H. The spectrum of cutaneous lymphomas in Japan: A study of 62 cases based on the World Health Organization Classification. J Cutan Pathol 2006;33:487-91.

10. Kerl H, Kodama K, Cerroni L. Diagnostic principles and new developments in primary cutaneous B-cell lymphomas. J Dermatol Sci 2004;34:167-75.

11. Cho-Vega JH, Vega F, Rassidakis G, Medeiros LJ. Primary cutaneous marginal zone B-cell lymphoma. Am J Clin Pathol 2006;(125 Suppl):S38-49. 